\title{
Grammar in the context of intersubjective usage
}

The linguistic work of Arie Verhagen

Dirk Geeraerts

\author{
NT 21 (3): 395-407 \\ DOI: 10.5117/NEDTAA2016.3.GEER
}

\begin{abstract}
For a scholar like Arie Verhagen, with his relentless curiosity and irrepressible research drive, retirement is merely an academic rite de passage and never a real retirement. Even so, the symbolic change of state is a fitting occasion to take stock of what has so far been achieved - pending further original contributions and novel insights. The following pages will first present a chronologically ordered overview of Arie Verhagen's linguistic work, and then bring out the importance of his contributions by briefly situating them in a wider context. In a very rough outline, the development of Arie Verhagen's linguistic thought may be characterized in three stages. (The references in the following pages are meant to be exemplary only. Drawing up, let alone discussing a comprehensive bibliography is beyond the reach of the present overview.)
\end{abstract}

Keywords: ? ?

\section{$1 \quad$ Functionalism versus formalism}

In an initial phase, which approximately covers the 1980s, Arie Verhagen's work is mainly concerned with word order phenomena. Adverb placement is the central theme, but the descriptive scope extends naturally to topics like dislocations, focus marking, or contrastive stress. The main publication issuing from this period is the dissertation (1986) that he wrote under the supervision of Dick (D.M.) Bakker and Theo Janssen at the Vrije Universiteit in Amsterdam. Theoretically speaking, Arie Verhagen's publications from this period are characterized by a sustained, conceptually thorough 
discussion with the formalist approaches that were then dominant in linguistics. As Arie Verhagen's own position is firmly anchored in a functionalist framework, it is instructive for an insight into his further evolution to see how he characterizes his point of view. Two features may be highlighted, each with a brief quotation from his dissertation. First, meaning is central in the definition of linguistic categories: 'What provides the basis for the unity of a category is the unity of the meaning of the form class' (1986: 15-16). Second, the systemic meaning of a category may be contextually modulated: 'A sign may occur, always with its one meaning, in different contexts (verbal and non-verbal), and the "sum" of the sign and its context may give rise to interpretations which are quite different from one case to another' (1986: 16; compare Verhagen 1997 for a later formulation of the point). Both features are methodologically important. The first one implies that a purely formal method of description, i.e. one that does not take into account meaning, is unrealistic: grammatical analysis requires an understanding of the expressions and utterances under investigation. The second feature implies that looking into the communicative contexts in which linguistic signs are used is an integral and indispensable part of linguistic methodology.

To fully appreciate the impact of this position, it needs to be situated against the theoretical landscape of linguistics in The Netherlands in the 1980s. Both universities in Amsterdam harbored a strong functionalist school: alongside the functionalist approaches at the Vrije Universiteit, Arie Verhagen's homeground, Simon Dik developed his Functional Grammar at the Universiteit van Amsterdam. These approaches were distinguished by a certain difference of focus: Dik's grammatical model had a strong typological orientation, whereas the perspective at the Vrije Universiteit veered more towards discourse and communication, with an explicit attention to the (con)texts in which linguistic signs appear. At the same time, generative grammar was an emphatic, if not to say militant, presence throughout linguistics in The Netherlands, which had been an enthusiastic early adopter of Chomskyan theories in the 1960s. Arie Verhagen's early work, then, is a fundamental confrontation with and rejection of a formalist methodology, but it also bears the imprint of the contextualizing rather than typological strand of functionalist thought. The main gist of Arie Verhagen's further development may now be characterized in a nutshell starting from these two features. On the one hand, while the attention to the fundamental questions and competing models behind the descriptive questions is a constant characteristic of his research, the focus of the debate shifts from the confrontation between formalism and functionalism 
to an internal discussion within the non-formalist, cognitive-functional family, more specifically, within Cognitive Linguistics. On the other hand, his most distinct and influential contributions to Cognitive Linguistics precisely continue the inspiration drawn from a context- and text-oriented form of functionalism.

\section{$2 \quad$ Aligning with Cognitive Linguistics}

The second stage in Arie Verhagen's development starts round 1990, when he enriches the functionalist background of the first phase with concepts and approaches that were then being developed in the emerging framework of Cognitive Linguistics (for an overview of the approach, see Geeraerts \& Cuyckens 2007). Cognitive Linguistics emerged round 1980 in the US in the work of Ron Langacker, Len Talmy, George Lakoff, Charles Fillmore and others, gaining a strong foothold in Europe in the second half of the 1980s. Penetration in The Netherlands was slowlier than in neighbouring countries like Germany and Belgium, though, and Arie Verhagen may be credited with a leading role in its propagation in The Netherlands. His rapprochement with Cognitive Linguistics is symbolically marked by a research stay as a visiting scholar at the Linguistics Department of the University of California, San Diego in 1990/1991, and also - tellingly for the authority he was soon able to build up in the Cognitive Linguistics community - by the fact that he led the main journal in the field, Cognitive Linguistics, from 1996 to 2004. Given his initial position as described in the previous paragraph, his adoption of a cognitive linguistic framework is hardly surprising. Here is a decidedly non-formalist approach that puts meaning center stage in linguistic description, and that furthermore defines linguistics as a usage-based approach (Langacker 1988), i.e. an approach that does not just concentrate on the linguistic system, but that includes the level of linguistic use, of parole rather than just langue, into the investigation. Two ideas in particular are important for the way in which Arie Verhagen incorporated the inspiration of Cognitive Linguistics: the notion of construction, and the relevance of subjectivity.

Construction grammar assumes that the grammar of a language does not take the form of a set of abstract rules, as in classical formalist accounts, but rather takes shape as an inventory of form/meaning pairings of which the formal side may range from almost entirely lexicalized expression types to abstract syntactic patterns. Arie Verhagen's work at this stage takes the form of in-depth analyses of various constructions, among 
them passives (Verhagen 1992, Cornelis \& Verhagen 1995), complementation and subordination (Verhagen 2001), the way construction (as in Dutch zich een weg banen; Verhagen 2003a, 2003b), and specifically also causal constructions of various kinds (Kemmer \& Verhagen 1994, Verhagen \& Kemmer 1997, Verhagen 1998, 2000a, 200ob, Stukker, Sanders \& Verhagen 2008, 2009). The perspective in these publications is predominantly contrastive in various ways, for instance in the sense of identifying the subtle distinctions between similar constructions in different languages (Verhagen $2007 \mathrm{~b}$ ), like the way construction in Dutch compared to English. More often, the contrastive view is language-internal, and the analysis focuses on the differences of construal between competing constructions, like passive versus active voice, or different causal connectives, or the Dutch causal auxiliaries doen and laten. General reflections and overviews on constructions as embodying different ways of perspectivizing events, situations, relations are Verhagen $(2005 \mathrm{~b})$ and $(2007 \mathrm{a})$. A third kind of contrast that plays a role in these constructional analyses is theoretical. Picking up the thread of comparing formalist and functionalist descriptions, some publications focus on phenomena that are so to speak household items in a generative model, trying to show that an analysis within a cognitive framework is more convincing. A prime example is Verhagen (2006), which offers a usage-based analysis of long-distance $w$ h-movement.

Characteristically, the comparison of the specific construals achieved by alternative constructions often invokes a second, more specific element from the conceptual repertoire of Cognitive Linguistics, viz. the concept of subjectivity. The conceptual basis of subjectivity is Langacker's notion of Ground, consisting of the circumstances and participants of a communicative event. Among other elements, the Ground comprises the subjects of conceptual construal (speaker and hearer) in contrast with the conceptualized object (roughly, a real or imagined situation or event). Subjectification, in Langacker's terms, involves the foregrounding of elements belonging to the Ground. In an utterance like the election will be held in November, the role of the speaking subject is not profiled. But in as far I know the election will be held in November, the presence of the speaker and his contribution to the conceptualization of the event is made explicit. Applied to constructions like the ones mentioned, this means for instance that different causal connectives can be distinguished according to the type of subjectivity they express. Dutch daardoor typically marks objective, non-volitional causality, daarom is used in cases of objective volitional causality, and dus expresses subjective, epistemic causality on the illocutionary level. Clearly, subjectification need not play a role in each and any type of con- 
struction, but Arie Verhagen suggests that some expressions that superficially do not seem to involve subjectification at all can be fruitfully reinterpreted from the perspective of subjectification. This is for instance where the het meisje dat beloofde iets te worden construction comes in ('the girl that promised to become something'). Verhagen (2000c) contrasts the two readings of the utterance: one in which the girl actively delivers a promise, and the other in which the utterance has a structure similar to the weather promises to be nice or the trip threatens to be cumbersome. The latter reading would normally be considered an objective construal, but Arie Verhagen points out that it expresses a judgement on the part of the speaker, and that it thus falls in the realm of subjectivity.

\section{$3 \quad$ Intersubjectivity and beyond}

The usage-based analysis of constructional construal that emerged in the 1990s continues to shape Arie Verhagen's work up to the present day, but even so, we may mark the publication of his monograph Constructions of Intersubjectivity (2005a) as triggering a third phase in his linguistic thinking. Essentially, the book involves a shift of perspective from subjectivity to intersubjectivity: the subjective nature of linguistic construal which gradually became more important in his discussion of specific constructions is now systematically interpreted as a potentially intersubjective phenomenon, that is to say, as a phenomenon involving cooperative communication (in the terminology of a more recent paper; Verhagen 2015). The recognition of intersubjectivity as a core notion seems to have occurred relatively suddenly early in the new millennium. In his inaugural lecture as professor of Dutch language and linguistics at the University of Leiden (2000d), it is not yet mentioned - even though this is a kind of text that tends to have a certain programmatic character. It does make an appearance in Verhagen (2000c) in the analysis of the construction type het meisje dat beloofde iets te worden 'the girl that promised to become something', but it does not yet have the prominent position that it gets in the book. The fundamental insight then is that cases of subjectification like those illustrated by promise should properly be seen as intersubjective messages: by profiling his or her presence, the speaker signals to the hearer that a common Ground is to be built up. Expressions profiling the speaker, in other words, can be seen as invitations for a conceptual coordination between speaker and hearer. In general, there are various linguistic phenomena, from discourse connectors to complementation patterns, that are best analyzed in terms of such a 
process of intersubjective coordination rather than (only) in terms of the relation between language, or speakers, and the world. A basic example of such a phenomenon is negation. Why does Mary is not happy allow a continuation with On the contrary, she is feeling really depressed, while adding that sentence is awkward after Mary is unhappy? From a purely logical or referential point of view the utterances Mary is not happy and Mary is unhappy are equivalent, but as intersubjective signals, they differ. Arie Verhagen suggests that the sentential negation, in contrast with the morphological one, is an instruction for the hearer to consider two mental spaces: one in which Mary is happy, and one in which that situation is denied. One could perhaps say that hearers reach the conclusion that Mary is sad directly in the case of Mary is unhappy, whereas mental processing takes two steps in the case of Mary is not happy: the construction with not instructs hearers to first consider Mary happy and then to reject that thought. The crucial point then is that the continuation with on the contrary is only licensed by the two-step process, because the contrast evoked by on the contrary precisely involves Mary being happy: for on the contrary to work, the thought of Mary being happy needs to be activated, and that is exactly, Arie Verhagen argues, what the sentential negation with not conventionally does. It will be appreciated how the framework outlined in the 2005 book retains the features introduced in the previous stage: subjectivity morphing into intersubjectivity on one hand, and on the other the notion of competing construals as choices made at the usage level. In this sense, the book epitomizes what went before, but it also ushers in a following phase in which new research accents emanating from the intersubjective perspective are pursued. Two of these stand out.

First, if intersubjectivity is a crucial design feature of language, it should not only be studied with a focus on the language as such, but it should just as well be considered with a focus on the linguistic community: how do the intersubjective interactions between the members of a speech community shape the evolution of the language in that community? This requires a model in which structure and usage are dialectically related, i.e. in which structure shapes usage, but in which structure may also emerge from usage. Ideas of this kind were already present in publications like Verhagen (2002a), but they now receive a more elaborate form (2009, 2010a). Specifically, in his diachronic work on causatives, Arie Verhagen (1998) had noticed a change in the semantic profile of the Dutch causative doen, which was originally used with both animate and inanimate causers, but which is now specialized for inanimate causation, and suggested an explanation in terms of the diminishing frequency of authority in descriptions of human 
interactions over the last three centuries - a cultural change, in other words. Examples such as these lead to the formulation of a general Darwinian model of the evolution of language and the emergence of structure from usage, albeit without any commitment to a strictly biological explanation of linguistic change (Verhagen 2004, 2008b, Zuidema \& Verhagen 2010, Landsbergen, Lachlan, Ten Cate \& Verhagen 2010). On the most general level, evolutionary change is defined as change in the relative frequencies of variants in a population. But in the case of language, that change is not driven by natural selection, but takes the form of cultural evolution. The underlying mechanism is the same, though: both biological and cultural evolution are population level phenomena, with change taking the form of the selection and transmission of variants. This perspective then also triggers an interest in the specifics of linguistic transmission at the level of the individual, that is to say, in usage-based models of language acquisition (see Brandt, Verhagen, Lieven \& Tomasello 2011, Beekhuizen, Bod \& Verhagen 2014, Beekhuizen, Bod, Fazly, Stevenson \& Verhagen 2014). And as before, the newly developed framework is to put to work to tackle typically generative concepts: in Verhagen (2008a, 2010b) it is suggested that syntactic recursion could be considered the result of cultural rather than strictly biological evolution.

Second, the perspective on intersubjectivity in the 2005 book is largely restricted to the manifestation of intersubjectivity in speakers - for instance, how the use of negation can be interpreted as an intersubjective invitation for cognitive coordination. But intersubjectivity also involves the recognition and representation of other people's point of view. In some of Arie Verhagen's most recent publications, this topic surfaces under the label of 'viewpoint', with a specific focus on the representation of multiple viewpoints in literary texts: Van Duijn, Sluiter \& Verhagen (2015), Verhagen (2016), Lu \& Verhagen (2016). Through which linguistic mechanisms, for instance, do narratives manage the transition between an auctorial point of view and the characters' voice? Such an application of linguistic analyses to literary texts is in fact a highly characteristic feature of Arie Verhagen's work that we haven't mentioned so far, but that runs like a thread through his scholarly production. Throughout his career, he has consistently and with great success tried to show how the models of analysis that he was working with, could lead to a better understanding of texts at large: poetry and other literary texts, but also persuasive texts and argumentative language: see Daalder \& Verhagen (1993), Verhagen (1995b, 200od, 2003b). This outspoken interest in stylistics obviously ties in with his communicative conception of language: if language is primarily to be seen as a com- 
municative tool, it should also be recognized that communication takes place in texts - larger units than the sentence level on which grammatical analysis focuses. The expansion from grammar to text analysis can actually be taken one step further. If a usage-based approach to language may lead to a better understanding of how usage works, it may also help language users to improve their language use. Stylistics then turns into practical rhetoric, and that perspective too is present in Arie Verhagen's work: see Onrust, Verhagen \& Doeve (1993), a handbook for efficient writing praxis, and Verhagen (2002b), a principled reflection on the relationship between theoretical linguistic analysis and rhetoric as applied stylistics. As this thread is being picked up again in his most recent work, constructional stylistics - the linguistically informed description of the stylistic, rhetorical, literary values of cognitive and intersubjective construals captured by alternative constructions - could well be the next focal point in Arie Verhagen's work.

\section{The grand scheme of things}

A chronological overview of the kind just presented reveals the natural logic with which research expands: initial themes and topics are developed in the interplay between their intrinsic momentum (original analyses leading to new observations leading to further inquiries - and continuing) and the inspiration derived from external sources. In a sense, the balance between these two influences characterizes the intellectual openness of a researcher, and in Arie Verhagen's case, it is outspoken and constitutive: his inquisitive attitude and his wide-ranging perspective have allowed him to cover a broad range of topics, to enter in discussion with diverse linguistic models, and to enrich his work accordingly. But how then can we situate Arie Verhagen's achievements in a wider context? If we take the perspective of linguistics at large - and specifically, the perspective of the evolution of linguistics during the course of Arie Verhagen's career - in what terms could we best describe the general characteristics of his work, over and above the specific importance of the contributions he has made to the various topics that were surveyed in the previous pages? Two interlocking dimensions are particularly relevant here: the evolution of different theoretical linguistic frameworks with regard to each other, and the internal evolution of Cognitive Linguistics as the theoretical model in which Arie Verhagen's work is most firmly placed. On the first dimension, Arie Verhagen is important as one of the people who have brought functional 
and Cognitive Linguistics closer together. On the second dimension, he is important as one of the people who embody the 'social turn' in Cognitive Linguistics.

The landscape of linguistics has changed considerably since the 1970s, when Arie Verhagen started his career. In the current post-Chomskyan era, the dominant position of formal grammar on the stage of linguistic theorizing has given way to a more diverse and in some sense more fragmented situation, in which a broad family of cognitive-functional approaches - all of them paying more attention to meaning and function than formalists tend to do - exists alongside the various manifestations of formal grammar. In the former group, Cognitive Linguistics is arguably the most widely appealing model (a feature to which the internal diversity of the approach most certainly contributes). Arie Verhagen then is not only a prominent figure within Cognitive Linguistics, but specifically also one of those who have brought functional and cognitive approaches closer together. In his comparison of cognitive and functional frameworks, Nuyts (2007: 546) aptly characterizes Arie Verhagen as a representative of functional-cognitive linguistics, meaning those strands of Cognitive Linguistics that achieve a blend with the functionalist traditions. In particular, that blend involves the introduction of an orientation on context and communication that is not prominently present in the work of core cognitive linguists like Lakoff, Talmy or Langacker.

At the same time, one of the features characterizing the internal evolution of Cognitive Linguistics is the growing importance of precisely such a communicative, contextualized perspective. As suggested in Geeraerts (2010), Cognitive Linguistics may be crucially seen as a recontextualizing approach to linguistics. Formal grammar, specifically when it restricts language to an innate autonomous syntax, dissociates the alleged core of language from meaning as expressing and shaping lived experience, from performance and language use, from the social aspects of language. Cognitive Linguistics by contrast embodies a systematic attempt to reintroduce those contextual elements in grammatical theorizing. The recontextualization only happens in stages, though. The emphasis on meaning is obviously there from the beginning: Cognitive Linguistics enters the scene of linguistics by introducing a new arsenal of concepts for describing meaning, from prototypes and radial networks over conceptual metaphors and image schemas to figure/ground alignments and active zones (and more). The usage-based nature of linguistics is also there from the beginning, but rather more as a background notion and not as a leading concept shaping the actual research practice. By and large, it is only by the beginning of the 
new millennium that the consequences of taking a usage-based approach to language are topicalized within Cognitive Linguistics, for instance in the growing importance of corpus data as repositories of actual language use. The intrinsically social nature of language use also enters the spotlights only in this later stage of development, in the various forms that are described in Geeraerts \& Kristiansen (2015). From the perspective of the internal evolution of Cognitive Linguistics, then, Arie Verhagen's intellectual trajectory - in particular, through the notion of intersubjective construal and its ramifications - a reflection of and a major contribution to this 'social turn' of Cognitive Linguistics. In other words, pursuing an inspiration that was already there in his earliest publications, Arie Verhagen's linguistic work embodies and strengthens some of the main trends of theoretical linguistics in the new millennium: overall, a movement away from formalist models, and more specifically within the cognitive-functionalist field, a tendency towards an increasingly usage-based, contextualizing point of view.

\section{References}

Beekhuizen, Barend, Rens Bod \& Arie Verhagen (2014). The linking problem is a special case of a general problem none of us has solved: Commentary on Ambridge, Pine, and Lieven. Language 90, e91-e96.

Beekhuizen, Barend, Rens Bod, Afsaneh Fazly, Suzanne Stevenson \& Arie Verhagen (2014). A Usage-Based Model of Early Grammatical Development. Proceedings of the Fifth Workshop on Cognitive Modeling and Computational Linguistics. <https://www.aclweb.org/anthology/ W/W14/W14-2006.pdf>

Brandt, Silke, Arie Verhagen, Elena Lieven \& Michael Tomasello (2011). German children's productivity with simple transitive and complement-clause constructions: Testing the effects of frequency and diversity. Cognitive Linguistics 22: 325-357.

Cornelis, Louise \& Arie Verhagen (1995). Does Dutch really have a passive? In: M. den Dikken \& K. Hengeveld (eds.), Linguistics in the Netherlands 1995. Amsterdam/Philadelphia: Benjamins, 49-6o.

Daalder, Saskia \& Arie Verhagen (1993). Dutch Tenses and the Analysis of a Literary Text. The Case of Marga Minco's De val. In: R.S. Kirsner (ed.), The Low Countries and Beyond. Lanham, MD: University Press of America, 139-150.

Duijn, Max J. Van, Ineke Sluiter \& Arie Verhagen (2015). When narrative takes over: The representation of embedded mindstates in Shakespeare's Othello. Language and Literature 24: 148-166.

Geeraerts, Dirk \& Hubert Cuyckens (eds.) (2007). The Oxford Handbook of Cognitive Linguistics. New York: Oxford University Press.

Geeraerts, Dirk (2010). Recontextualizing grammar: Underlying trends in thirty years of Cognitive Linguistics. In: E. Tabakowska, M. Choinski \& L. Wiraszka (eds.), Cognitive Linguistics in Action: From Theory to Application and Back. Berlin/New York: De Gruyter Mouton, 71-102. 
Geeraerts, Dirk \& Gitte Kristiansen (2015). Variationist linguistics. In: E. Dąbrowska \& D. Divjak (eds.), Handbook of Cognitive Linguistics. Berlin: De Gruyter Mouton, 366-389.

Kemmer, Suzanne \& Arie Verhagen (1994). The grammar of causatives and the conceptual structure of events. Cognitive Linguistics 5, 115-156.

Landsbergen, Frank, Robert Lachlan, Carel ten Cate \& Arie Verhagen (2010). A cultural evolutionary model of patterns in semantic change. Linguistics 48, 363-390.

Langacker, Ronald W. (1988). A usage-based model. In: B. Rudzka-Ostyn (ed.), Topics in Cognitive Linguistics. Amsterdam/Philadelphia: Benjamins, 127-161.

Lu, Wei-lun \& Arie Verhagen (2016). Shifting viewpoints: How does that actually work across languages? An exercise in parallel text analysis. In: B. Dancygier, W. Lu \& A. Verhagen (eds.), Viewpoint and the Fabric of Meaning. Form and Use of Viewpoint Tools across Languages and Modalities. Berlin/Boston: De Gruyter Mouton, 169-190.

Nuyts, Jan (2007). Cognitive linguistics and functional linguistics. In: D. Geeraerts \& H. Cuyckens (eds.), The Oxford Handbook of Cognitive Linguistics. Oxford: Oxford University Press, 543565 .

Onrust, Margreet, Arie Verhagen \& Rob Doeve (1993). Formuleren. Houten/Diegem: Bohn Stafleu Van Loghum.

Stukker, Ninke, Ted Sanders \& Arie Verhagen (2008). Causality in verbs and in discourse connectives. Converging evidence of cross-level parallels in Dutch linguistic categorization. Journal of Pragmatics 40: 1296-1322.

Stukker, Ninke, Ted Sanders \& Arie Verhagen (2009). Categories of subjectivity in Dutch causal connectives: a usage-based analysis. In: Ted Sanders \& Eve Sweetser (eds.), Causal Categories in Discourse and Cognition. Berlin/New York: Mouton de Gruyter, 119-171.

Verhagen, Arie (1986). Linguistic Theory and the Function of Word Order in Dutch. A study on interpretive aspects of the order of adverbials and noun phrases. Dordrecht: Foris.

Verhagen, Arie (1992). Praxis of linguistics: passives in Dutch. Cognitive Linguistics 3, 301-342.

Verhagen, Arie (1995a). Subjectification, syntax, and communication. In: D. Stein \& S. Wright (eds.), Subjectivity and subjectivisation: linguistic perspectives. Cambridge: Cambridge University Press, 103-128.

Verhagen, Arie (1995b). Taal- en toch letterkunde. Forum der Letteren 36, 335-340

Verhagen, Arie (1997). Context, meaning, and interpretation, in a practical approach to linguistics. In: L. Lentz \& H.L.W. Pander Maat (eds.), Discourse analysis and evaluation. Amsterdam: Rodopi, 7-39.

Verhagen, Arie \& Suzanne Kemmer (1997). Interaction and causation: Causative constructions in modern standard Dutch. Journal of Pragmatics 27, 61-82.

Verhagen, Arie (1998). Changes in the use of Dutch doen and the nature of semantic knowledge. In: I. Tieken-Boon van Ostade, M. van der Wal \& A. van Leuvensteijn (eds.), DO in English, Dutch and German. History and present-day variation. Amsterdam/Münster: Stichting Neerlandistiek/Nodus Publikationen, 103-119.

Verhagen, Arie (2000a). Concession implies causality, though in some other space. In: E. CouperKuhlen \& B. Kortmann (eds.), Cause - Condition - Concession - Contrast: Cognitive and discourse perspectives. Berlin: Mouton de Gruyter, 361-380.

Verhagen, Arie (20oob). Interpreting Usage: Construing the History of Dutch Causal Verbs. In: M. Barlow \& S. Kemmer (eds.), Usage-Based Models of Language. Stanford, CA: CSLI Publications, 261-286.

Verhagen, Arie (2000c). "The girl that promised to become something": An exploration into diachronic subjectification in Dutch. In: T.F. Shannon \& J.P. Snapper (eds.), The Berkeley Conference on Dutch Linguistics 1997: the Dutch Language at the Millennium. Lanham, MD: University Press of America, 197-208. 
Verhagen, Arie (200od). Achter het Nederlands. Over interacties tussen taal en achtergrondcognitie. [Rede uitgesproken door Arie Verhagen bij de aanvaarding van het ambt van hoogleraar Nederlandse Taalkunde.] Leiden: Universiteit Leiden.

Verhagen, Arie (2001). Subordination and discourse segmentation revisited, or: Why matrix clauses may be more dependent than complements. In: T. Sanders, J. Schilperoord \& W. Spooren (eds.). Text Representation. Linguistic and psycholinguistic aspects. Amsterdam: Benjamins, 337-357.

Verhagen, Arie (2002a). From parts to wholes and back again. Cognitive Linguistics 13, 403-439.

Verhagen, Arie (2002b). Retorica en cognitie. In: Th. Janssen (ed.), Taal in gebruik. Een inleiding in de taalwetenschap. Den Haag: Sdu Uitgevers, 97-110.

Verhagen, Arie (2003a). The Dutch way. In: A. Verhagen \& J. van de Weijer (eds.), Usage-Based Approaches to Dutch. Utrecht: LOT, 27-57.

Verhagen, Arie (2003b). Hoe het Nederlands zich een eigen weg baant. Vergelijkende en historische observaties vanuit een constructie-perspectief. Nederlandse Taalkunde 8, 328-346.

Verhagen, Arie $(2003 \mathrm{c})$. Semantics, Inferential Cognition, and Understanding Text. In: E. van Wolde (ed.), Job 28. Cognition in Context (Biblical Interpretation Series, Volume 64). Leiden: Brill, 231-252.

Verhagen, Arie (2004). Language, culture, nature: exploring new perspectives. In: A. Soares da Silva, A. Torres, M. Gonçalves (eds.), Linguagem, Cultura e Cognição: Estudos de Linguística Cognitiva. Coimbra: Almedina, 165-187.

Verhagen, Arie (2005a). Constructions of Intersubjectivity. Discourse, Syntax, and Cognition. Oxford: Oxford University Press.

Verhagen, Arie (2005b). Constructiegrammatica en 'usage based' taalkunde. Nederlandse Taalkunde 10: 197-222.

Verhagen, Arie (2006). On subjectivity and 'long distance Wh-movement'. In: A. Athanasiadou, C. Canakis \& Bert Cornillie (eds.), Subjectification: Various Paths to Subjectivity. Berlin/New York: Mouton de Gruyter, 323-346.

Verhagen, Arie (2007a). Construal and perspectivisation. In: D. Geeraerts \& H. Cuyckens (eds.), The Oxford Handbook of Cognitive Linguistics. Oxford: Oxford University Press, 48-81.

Verhagen, Arie (2007b). English constructions from a Dutch perspective: Where are the differences? In: M. Hannay \& G.J. Steen (eds.), Structural-functional studies in English grammar. In honour of Lachlan Mackenzie. Amsterdam /Philadelphia: Benjamins, 257-274.

Verhagen, Arie (2008a). Syntax, recursion, productivity - a usage-based perspective on the evolution of grammar. In: A. Lubotsky, J. Schaeken \& J. Wiedenhof (eds.), Evidence and Counterevidence, Festschrift F. Kortlandt, Volume 2 (SSGL 33). Amsterdam - New York: Rodopi, 399414.

Verhagen, Arie (2008b). Intersubjectivity and the architecture of the language system. In: J. Zlatev, T.P. Racine, C. Sinha \& E. Itkonen (eds.), The Shared Mind: Perspectives on Intersubjectivity. Amsterdam/Philadelphia: Benjamins, 307-331.

Verhagen, Arie (2009). The conception of constructions as complex signs. Emergence of structure and reduction to usage. Constructions and Frames 1119-152.

Verhagen, Arie (2010a). Usage, structure, scientific explanation, and the role of abstraction, by linguists and by language users. In: Kasper Boye \& Elisabeth Engberg-Pedersen (eds.), Language Usage and Language Structure. Berlin/New York: De Gruyter Mouton, 45-72.

Verhagen, Arie (2010b). What do you think is the proper place of recursion? Conceptual and empirical issues. In: Harry van der Hulst (ed.), Recursion and Human Language. Berlin/New York: De Gruyter Mouton, 93-110.

Verhagen, Arie (2015). Grammar and cooperative communication. In: Ewa Dąbrowska \& Dagmar Divjak (eds.), Handbook of Cognitive Linguistics. Berlin/Boston: De Gruyter Mouton, 232-252. 
Verhagen, Arie (2016). Introduction: On tools for weaving meaning out of viewpoint threads. In: B. Dancygier, W. Lu \& A. Verhagen (eds.), Viewpoint and the Fabric of Meaning. Form and Use of Viewpoint Tools across Languages and Modalities. Berlin/Boston: De Gruyter Mouton, 1-10.

Zuidema, Willem \& Arie Verhagen (2010). What are the unique design features of language? Formal tools for comparative claims. Adaptive Behavior 18, 48-65.

\section{About the author}

Dirk Geeraerts, Departement Linguïstiek, K.U.Leuven.

E-mail: dirk.geeraerts@arts.kuleuven.be 